\title{
Correction to: Effect of Intravitreal Injections on Retinal Imaging Metrics in Glaucomatous and Non-Glaucomatous Eyes
}

\author{
Ronaldo Nuesi ${ }^{1,2} \cdot$ Swarup S. Swaminathan ${ }^{1}$ \\ Published online: 13 July 2020 \\ (C) Springer Science+Business Media, LLC, part of Springer Nature 2020
}

\section{Correction to: Current Ophthalmology Reports. https://doi.org/10.1007/s40135-020-00235-z}

The original version of this article unfortunately contained a mistake. The sentence "Despite no clear correlation between intravitreal injections and retinal thinning, attempts have been made to mitigate the potential effects of post-injection IOP spikes [61]." was deleted without any instruction from the author.

The original version has been corrected.

Publisher's Note Springer Nature remains neutral with regard to jurisdictional claims in published maps and institutional affiliations.

The online version of the original article can be found at https://doi.org/ $10.1007 / \mathrm{s} 40135-020-00235-\mathrm{Z}$

Swarup S. Swaminathan

sswaminathan@miami.edu

Ronaldo Nuesi

rnues001@med.fiu.edu

1 Department of Ophthalmology, Bascom Palmer Eye Institute, University of Miami Miller School of Medicine, 900 NW 17th St, Miami, FL 33136, USA

2 Herbert Wertheim College of Medicine, Florida International University, Miami, FL 33199, USA 